\section{Diverse classification systems for maxillectomy defects: Simplifying or complicating the treatment plan?}

Sir,

Apropos the article titled "Recent advances in head and neck cancer reconstruction" published in your esteemed journal, ${ }^{[1]}$ we commend Yadav P. for putting forth an enlightening review of the progress made in the field of microvascular reconstruction techniques which are now being amalgamated with technology, for improved rehabilitation of patients following surgical treatment of head and neck cancer. Yadav P. has rightly mentioned that for maxillectomy defects, reconstruction algorithms have been individual or institute based. ${ }^{[1]}$ In this regard, we opine that lack of a universally applicable/acceptable classification system for maxillectomy defects has complicated the communication and treatment planning among various specialties involved in the management of such defects.

There are around 14 different classification schemes for maxillectomy defects. ${ }^{[2]}$ These classifications are based on the nature of the procedure performed or on the resultant tissue loss or the extent of surgical resection or by taking into consideration the prosthodontist's perspective after completion of healing. ${ }^{[2]}$ However, none of the existing classifications have integrated all the factors, which are considered significant by different disciplines involved in the management of maxillectomy patients.

The facts worth realising are that the dental rehabilitation is not accomplished by surgical reconstruction alone and likewise, in non-reconstructed defects, implant retained/ supported fixed dental prosthetic rehabilitation may not be possible. Before the advent and use of osseointegrated implants for dental rehabilitation, removable prosthetic rehabilitation with obturatorwas the only treatment option available for maxillectomy patients. However, placement (either primary or secondary) of osseointegrated implants in the maxilla that has been reconstructed with bone grafts has revolutionised the treatment and rehabilitation of such patients, thereby improving their quality of life..$^{[3]}$

For successful rehabilitation, close collaboration between surgical oncologist, plastic surgeon and maxillofacial prosthodontist is necessary and for effective communication among them, a common terminology/ classification is a must, to avoid confusions and ambiguity. Yadav P. has mentioned that Brown's classification is simple to use. But, as prosthodontists, we commonly use Aramany's classification since Brown's classification doesn't adequately address the factors/issues that are of concern to us. So, when a surgeon says Class I defect (according to surgical/Brown's classification), ${ }^{[1,2]}$ it refers to a different defect than when a prosthodontist says Class I defect (according to prosthetic/Aramany's ${ }^{[4]}$ or Okay's et al. classification ${ }^{[5]}$ ), which in many situations complicates the communication. Hence there is an utmost need of a comprehensive classification system for maxillectomy defects, which takes into account the multitude of factors necessary to rehabilitate such patients and which has been critically evaluated by the managing multidisciplinary team to reach a consensus.

\section{Himanshi Aggarwal, Prashanti Eachempati ${ }^{1}$, Pradeep Kumar}

Department of Prosthodontics, Faculty of Dental Sciences, King George's Medical University, Lucknow, Uttar Pradesh, India, 'Departments of Prosthodontics, Faculty of Dentistry, Melaka Manipal Medical College, Melaka, Malaysia

Address for correspondence:

Dr. Pradeep Kumar, Room No. 404, E Block, Gautam Buddha Hostel, King George's Medical University, Lucknow, Uttar Pradesh, India. E-mail: drpradeepkmr@gmail.com

\section{REFERENCES}

1. Yadav P. Recent advances in head and neck cancer reconstruction. Indian J Plast Surg 2014;47:185-90.

2. Bidra AS, Jacob RF, Taylor TD. Classification of maxillectomy defects: A systematic review and criteria necessary for a universal description. J Prosthet Dent 2012;107:261-70.

3. Kumar P, Alvi HA, Rao J, Singh BP, Jurel SK, Kumar L, et al. Assessment of the quality of life in maxillectomy patients: A longitudinal study. J Adv Prosthodont 2013;5:29-35.

4. Aramany MA. Basic principles of obturator design for partially edentulous patients. Part I: Classification. J Prosthet Dent 1978;40:554-7.

5. Okay DJ, Genden E, Buchbinder D, Urken M. Prosthodontic guidelines for surgical reconstruction of the maxilla: A classification system of defects. J Prosthet Dent 2001;86:352-63.

\begin{tabular}{|l|l|}
\hline \multicolumn{2}{|c|}{ Access this article online } \\
\hline Quick Response Code: & Website: \\
\hline & www.ijps.org \\
\cline { 2 - 2 } & Dol: \\
\hline
\end{tabular}

